\title{
Low vitamin D levels are associated with cognitive impairment in patients with Hashimoto thyroiditis
}

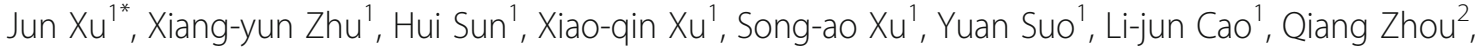
Hui-jie $Y u^{1}$ and Wei-zhong Cao ${ }^{1}$

\begin{abstract}
Background: Cognitive impairment is commonly observed in patients with Hashimoto thyroiditis (HT). Low levels of vitamin D have been correlated with cognitive impairment in non-HT population. We examined the association of vitamin D levels with cognitive impairment in patients with HT.

Methods: We recruited 194 patients with HT and 200 healthy volunteers. Levels of serum 25-hydroxyvitamin D $(25(\mathrm{OH}) \mathrm{D})$ were measured using a competitive protein-binding assay. Cognitive funtion was assessed using Montreal Cognitive Assessment score (MoCA). Subjects with a MoCA scores $<26$ are considered as having mild cognitive impairment $(\mathrm{MCl})$. Multivariate analysis was performed using logistic regression models.

Results: Fifty-five HT patients (28.4\%) were diagnosed as having MCl. Patients with MCI had significantly lower $25(\mathrm{OH}) \mathrm{D}$ levels when compared with patients without $\mathrm{MCl}(33.9 \pm 6.2 \mathrm{vs} .44 .3 \pm 9.6 \mathrm{nmol} / \mathrm{L}, P<0.001)$. Significant differences in $25(\mathrm{OH}) \mathrm{D}$ quartiles of HT patients were observed between the patients with $\mathrm{MCl}$ and the patients without $\mathrm{MCl}(P<0.001)$. In multivariate analyses, serum $25(\mathrm{OH}) \mathrm{D}$ levels $(\leq 34.0$ and $\geq 47.1 \mathrm{nmol} / \mathrm{L})$ were significantly associated with cognitive impairment in patients with HT (OR 6.279, 95\% Cl 2.673-14.834, $P<0.001 ;$ OR 0.061, 95\% Cl 0.008-0.491, $P=0.009$, respectively).

Conclusion: Our results demonstrate an important association between serum vitamin D levels and cognitive impairment in patients with HT.
\end{abstract}

Keywords: Hashimoto's thyroiditis, Vitamin, Cognitive impairment, Montreal cognitive assessment

\section{Background}

Hashimoto thyroiditis (HT) is a common chronic autoimmune disease of the thyroid gland, characterized by painless goiter and elevated thyroid antibodies. A growing number of studies suggest cognitive impairment in patients with HT, independently of thyroid function disorders $[1,2]$. Cognitive impairment has been associated with increased risk of depression and impaired activities of daily living in patients with chronic diseases [3, 4]. Therefore, it is important to identify risk factors for the presence of cognitive impairment in patients with HT.

\footnotetext{
* Correspondence: jiaxingxujun@163.com

${ }^{1}$ Department of Emergency, First Affiliated Hospital of Jiaxing University, Jiaxing, Zhejiang Province, China

Full list of author information is available at the end of the article
}

In addition to its well-known significance in the regulation of calcium-phosphorus metabolism, vitamin D may have neuroprotective properties by suppressing inflammation and oxidative stress [5-7]. Vitamin D receptors and vitamin $\mathrm{D}$ activating enzyme $1 \alpha$-hydroxylase are broadly present in the hippocampus, hypothalamus, cortex and subcortex, the regions essential for cognition $[8,9]$. Emerging clinical studies suggest an association between low vitamin $\mathrm{D}$ levels and cognitive impairment in adults and non-HT patients with chronic kidney disease, type 2 diabetes, as well as Alzheimer's disease [10-14].

Hypovitaminosis D (vitamin D insufficiency and deficiency) is common among patients with HT [15-17]. Up to now, however, no study has explored the possible association between vitamin $\mathrm{D}$ levels and cognitive 
impairment in patients with HT. Given the involvement of vitamin D in cognitive impairment among non-HT subjects and the high prevalence of hypovitaminosis $\mathrm{D}$ in patients with $\mathrm{HT}$, whether vitamin D levels are related to cognitive impairment in HT patients was examined.

\section{Methods}

\section{Study sample}

Of 212 patients diagnosed as HT were consecutively recruited from the First Affiliated Hospital of Jiaxing University between 16 March 2014 and 24 February 2017. Diagnosis of HT was based on positive anti-thyroid peroxidase antibodies (TPOAbs) and/or anti-thyroglobulin antibodies (TgAbs), associated with a ultrasound patterns suggestive of HT. Eligibility criteria included: (1) Chinese ethnicity; (2) age from 18 to 60 years; (3) stable L-thyroxine treatment; (4) harboring the willingness to give informed consent. Exclusion criteria were: (1) patients with a history of other endocrine diseases; (2) patients with a history of cognitive or psychiatric disorders; (3) patients with a history of osteoporosis; (4) patients receiving vitamin $\mathrm{D}$ replacement therapy. Meanwhile, 200 healthy volunteers without any euthyroid, neurological or psychiatric diseases, were recruited from a health survey of the same regions.

\section{Clinical variables}

Demographic and clinical variables were obtained from participant report and electronic medical records. Demographic inclued age, sex, body mass index (BMI) and education. BMI was calculated as weight $(\mathrm{kg}) /$ squared height $\left(\mathrm{m}^{2}\right)$. A fasting morning venous blood sample was obtained from each participant. Levels of serum thyroid-stimulating hormone (TSH), free-triiodothyronine (FT3), free thyroxine (FT4), TgAbs, and TPOAbs were determined with automated immuno chemiluminescent assay (ICMA) kits (Abbott Laboratories, IL, USA). Levels of serum 25-hydroxyvitamin D $(25(\mathrm{OH}) \mathrm{D})$ were determined using a competitive protein-binding assay (Roche Diagnostics, Mannheim, Germany). The inter-assay variation coefficient for $25(\mathrm{OH}) \mathrm{D}$ measurement was $8.5 \%$. Serum 25(OH)D levels in HT patients were divided into four quartiles ( $\leq 34.0,34.1-40.0,40.1-47.0$ and $\geq 47.1$ $\mathrm{nmol} / \mathrm{L}$ ), as the raw data of $25(\mathrm{OH}) \mathrm{D}$ were skewed. The median 25-hydroxyvitamin $\mathrm{D}$ values for all quartiles were 30.8, 36.6, 43.7 and $53.1 \mathrm{nmol} / \mathrm{L}$, respectively.

\section{Neuropsychological testing}

Cognitive funtion was assessed using Montreal Cognitive Assessment score (MoCA), a simple cognitive screening tool with superior sensitivity [18]. The MoCA is a one-page 30-point test that can be administered in 10 min. It covers important cognitive domains, including short-term memory, visuospatial abilities, executive functions, attention, concentration, working memory, and language, together with orientation to time and place. Based on the MoCA scoring system, patients were divided into two groups: the patients who had MoCA scores $<26$ were selected as mild cognitive impairment (MCI) group, and the other patients who had MoCA scores of 26 or greater were selected as the group without MCI. These evaluations were administered by the same experienced psychologist who was blind to the laboratory results of HT patients.

\section{Statistical analysis}

Data were presented as number (percentage) for categorical variables, mean \pm standard deviation (SD) for normally distributed variables, and medians (25th, 75th percentiles) for non-normally distributed variables. Comparisons between the groups were conducted using the $\chi^{2}$ test, Fisher's exact test, Student $t$ test, and MannWhitney $U$ test, as appropriate. Binary logistic regression including age, sex, and the factors with $P<0.10$ in the univariate analysis, was performed to examine significant risk factors for cognitive impairment in HT patients. The abnormally distributed parameters were log-transformed for satisfying the log-linearity assumption. The results were presented as odds ratios (OR) with corresponding 95\% confidence intervals (CI). All Statistical analysis were performed by using SPSS 22.0 (Chicago, IL). Significance level was defined as $P<0.05$.

\section{Results}

Baseline characteristics of study samples

Of 212 patients with HT, 18 were excluded from this analysis: 2 with a history of dementia, 6 taking vitamin $\mathrm{D}$ replacement therapy, and 10 who refused to participate in this study. There were no significant differences in age and sex between our study cohort $(N=194)$ and those excluded. Of 194 participants, 158 were male (81.4\%) and their mean (SD) age was 49.4 (9.8) years. The patients in this study did not differ from the controls in terms of age, sex, BMI, education, as well as levels of TSH, FT3, and FT4 (all $P>0.05$ ) (Table 1).

\section{Univariate associations}

Of the 194 patients who formed the study sample, 55 (28.4\%, 42 female, 13 male) were diagnosed with MCI. Serum levels of $25(\mathrm{OH}) \mathrm{D}$ were markedly lower in patients with HT than in healthy controls (40.4 (34.3-46.9) vs. $58.3(52.1-64.8) \mathrm{nmol} / \mathrm{L}, P<0.001)$. There was a postive correlation between 25(OH)D levels and MoCA scores $(r=0.828, P<0.001$; Fig. 1a). Compared with patients without MCI, patients with MCI had significantly lower $25(\mathrm{OH}) \mathrm{D}$ levels $(33.9 \pm 6.2$ vs. $44.3 \pm 9.6 \mathrm{nmol} / \mathrm{L}, P$ $<0$. 001), while serum TSH, FT3, FT4, and antibodies levels were not different. 25(OH)D levels were inversely 
Table 1 Characteristics of HT patients and controls

\begin{tabular}{llll}
\hline Characteristics & Patients with HT & Controls & \\
\hline Number of patients & 194 & 200 & \\
Age (years), mean $\pm(\mathrm{SD})$ & $49.4 \pm 9.8$ & $48.6 \pm 9.1$ & $43 / 157$ \\
Sex (female/male) & $36 / 158$ & $12(9-14)$ & 0.352 \\
Educaton (years), median (IQR) & $11(8-14)$ & $24.5 \pm 3.3$ & 0.466 \\
BMI (kg/m2), mean $\pm(\mathrm{SD})$ & $24.2 \pm 3.2$ & $2.0 \pm 0.8$ & 0.437 \\
TSH (IU/mL), mean $\pm(\mathrm{SD})$ & $2.2 \pm 0.9$ & $4.6 \pm 1.2$ & 0.169 \\
FT3 (pmol/L), mean $\pm(\mathrm{SD})$ & $4.8 \pm 1.1$ & $18.6 \pm 4.7$ & 0.229 \\
FT4 (pmol/L), mean $\pm(\mathrm{SD})$ & $18.1 \pm 4.4$ & $58.3(52.1-64.8)$ & 0.254 \\
25(OH)D (nmol/L), median (IQR) & $40.4(34.3-46.9)$ & $<0.001$
\end{tabular}

Data are expressed as number (percentage) or means ( \pm SD) or medians (IQR). Abbreviations: HT Hashimoto thyroiditis, BMI Body mass index, TSH Thyroidstimulating hormone, FT3 Free-triiodothyronine, FT4 Free thyroxine, 25(OH)D 25-hydroxyvitamin D

correlated with TPOAbs levels $(r=-0.316, P<0.001$; Fig. 1b). No correlation was observed between 25(OH)D levels and age, sex, BMI, education, as well as levels of TSH, FT3, FT4, and TgAbs (all $P>0.05$ ). Significant differences in $25(\mathrm{OH}) \mathrm{D}$ quartiles of HT patients were detected between the patients with $\mathrm{MCI}$ and the patients without MCI $(P<0.001)$ (Table 2$)$.

\section{Multivariate regressions}

With all HT patients taken as a whole, quartile 2 and quartile 3 taken as the references used for serum 25(OH)D levels, and cognitive impairment taken as a dependent variable in the logistic analysis, serum $25(\mathrm{OH}) \mathrm{D}$ levels $(\leq 34.0$ and $\geq 47.1 \mathrm{nmol} / \mathrm{L})$ were significantly associated with cognitive impairment in patients with HT (OR 6.279, 95\% CI 2.673-14.834, $P<0.001$; OR $0.061,95 \%$ CI $0.008-0.491, P=0.009$, respectively) (Table 3).

\section{Discussion}

To our knowledge, this is the first study examining the possible association of serum level of vitamin D with cognitive impairment in patients with HT. Our results suggest that serum vitamin $D$ levels were significantly associated with cognitive impairment in HT patients, which is similar to earlier studies in adults and non-HT patients with chronic kidney disease, type 2 diabetes, as well as Alzheimer's disease [1014]. Further studies shuold be encouraged to examine the preventive and therapeutic effects of vitamin $\mathrm{D}$ on cognitive impairment in patients with HT. Moreover, Yasmeh et al. reported that $25(\mathrm{OH}) \mathrm{D}$ levels for the HT and controls were significantly different in females but not in males. But no correlation was observed between $25(\mathrm{OH}) \mathrm{D}$ levels and sex in the current study. Further studies are needed to determine the sex difference of $25(\mathrm{OH}) \mathrm{D}$ levels in HT patients.

Vitamin D receptors and vitamin D activating enzyme $1 \alpha$-hydroxylase are broadly expressed in the hippocampus, hypothalamus, cortex and subcortex, the regions essential for cognitive function [8, 9]. Additionally, emerging experimental studies suggest an important neuroprotective role of vitamin $\mathrm{D}$ by mediating
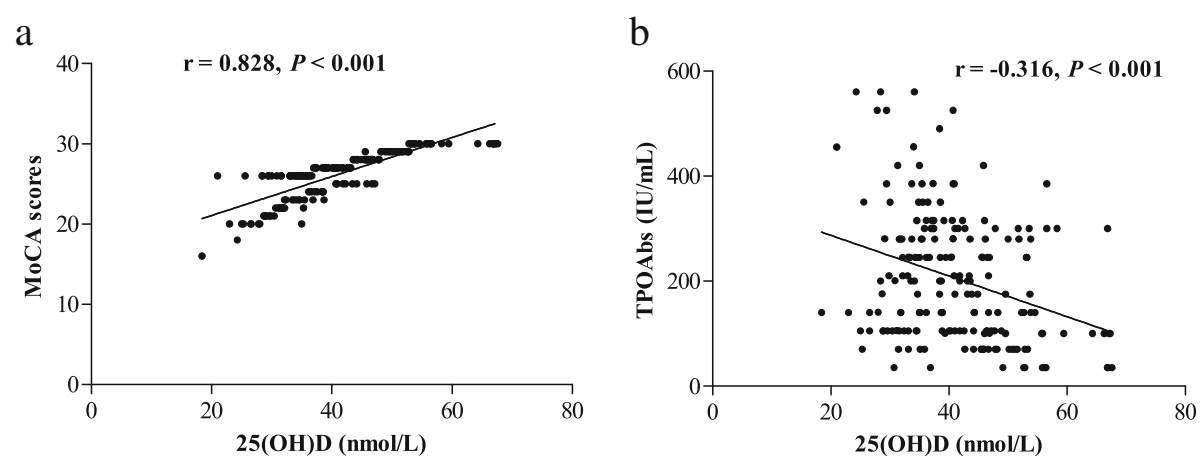

Fig. 1 The correlation between serum 25(OH)D levels and a MoCA scores as well as TPOAbs levels. Abbreviations: MoCA, Montreal Cognitive Assessment score; 25(OH)D, 25-hydroxyvitamin D; b TPOAbs, anti-thyroid peroxidase antibodies 
Table 2 Patient characteristics stratified by MCl

\begin{tabular}{|c|c|c|c|}
\hline Characteristics & Patients with $\mathrm{MCl}$ & Patients without $\mathrm{MCl}$ & $P$ \\
\hline Number of patients & 55 & 139 & \\
\hline Age (years), mean $\pm(S D)$ & $46.7 \pm 9.0$ & $50.5 \pm 9.9$ & 0.014 \\
\hline Sex (female/male) & $13 / 42$ & $23 / 116$ & 0.252 \\
\hline Educaton (years), median (IQR) & $13(8-17)$ & $11(8-14)$ & 0.074 \\
\hline $\mathrm{BMI}(\mathrm{kg} / \mathrm{m} 2)$, mean $\pm(\mathrm{SD})$ & $23.6 \pm 3.1$ & $24.5 \pm 3.2$ & 0.092 \\
\hline $\mathrm{TSH}(\mathrm{IU} / \mathrm{mL})$, mean $\pm(\mathrm{SD})$ & $2.3 \pm 0.8$ & $2.1 \pm 0.9$ & 0.336 \\
\hline FT3 (pmol/L), mean $\pm(S D)$ & $4.7 \pm 1.0$ & $4.8 \pm 1.1$ & 0.541 \\
\hline FT4 (pmol/L), mean $\pm(S D)$ & $17.9 \pm 3.9$ & $18.2 \pm 4.6$ & 0.710 \\
\hline TPOAbs (IU/mL), median (IQR) & $210.1(105.0-280.8)$ & $175.4(100.6-280.6)$ & 0.244 \\
\hline TgAbs (IU/mL), median (IQR) & $221.2(201.5-282.3)$ & $213.5(190.3-248.5)$ & 0.135 \\
\hline $25(\mathrm{OH}) \mathrm{D}(\mathrm{nmol} / \mathrm{L})$, mean $\pm(\mathrm{SD})$ & $33.9 \pm 6.2$ & $44.3 \pm 9.6$ & $<0.001$ \\
\hline 25(OH)D, No. (\%) & & & $<0.001$ \\
\hline Quartile $1(30.8 \mathrm{nmol} / \mathrm{L})^{\mathrm{a}}$ & $29(52.7)$ & $20(14.4)$ & $<0.001$ \\
\hline Quartile $2(36.6 \mathrm{nmol} / \mathrm{L})^{\mathrm{a}}$ & $14(25.5)$ & $31(23.3)$ & 0.639 \\
\hline Quartile $3(43.7 \mathrm{nmol} / \mathrm{L})^{\mathrm{a}}$ & $10(18.2)$ & $40(28.8)$ & 0.128 \\
\hline Quartile $4(53.1 \mathrm{nmol} / \mathrm{L})^{\mathrm{a}}$ & $2(3.6)$ & $48(34.5)$ & $<0.001$ \\
\hline
\end{tabular}

Data are expressed as number (percentage) or means ( \pm SD) or medians (IQR). Abbreviations: MCI Mild cognitive impairment, $B M I$ Body mass index, TSH Thyroidstimulating hormone, FT3 Free-triiodothyronine, FT4 Free thyroxine, TPOAbs Anti-thyroid peroxidase antibodies, TgAbs Antithyroglobuline antibodies, 25(OH)D 25-hydroxyvitamin D

aThe median 25-hydroxyvitamin D values for each quartile

expression of neurotransmitters, improving neurogenesis, and preventing amyloid- $\beta$ accumulation [19-21]. Studies on vitamin D receptors knockout mice have shown that hypovitaminosis D may play a role in behavioural, motor and sensory deficits, all of which can contribute to cognitive impairment [22-24]. In line with these results, clinical evidence shows that low levels of vitamin $\mathrm{D}$ is associated with cognitive impairment.

The exact role of vitamin D in the pathophysiology of cognitive impairment in HT patients is not yet clear. A possible explanation is the effect of vitamin D on inflammatory cytokines. Previous studies showed an increased cytokine production, including interleukin-1 $\beta$ (IL-1 $\beta$ ),

Table 3 Characteristics associated with $\mathrm{MCl}$ in patients with $\mathrm{HT}$

\begin{tabular}{lll}
\hline Characteristics & OR $(95 \% \mathrm{Cl})$ & $P$ \\
\hline 25(OH)D & & \\
Quartile 1 & $6.279(2.673-14.834)$ & $<0.001$ \\
Quartile 4 & $0.061(0.008-0.491)$ & 0.009 \\
Sex & $1.153(0.487-2.728)$ & 0.746 \\
Age & $1.022(0.978-1.068)$ & 0.323 \\
Education & $1.040(0.982-1.102)$ & 0.176 \\
BMl & $0.909(0.810-1.020)$ & 0.103 \\
\hline
\end{tabular}

Abbreviations: $M C I$ Mild cognitive impairment, $H T$ Hashimoto thyroiditis, 25(OH)D 25-hydroxyvitamin D, BMI Body mass index interleukin-6 (IL-6), monocyte chemoattractant protein-1 (MCP-1), and tumor necrosis factor alpha (TNF- $\alpha$ ), in HT patients [25, 26]. Vitamin D has been involved in modulating the secretion of cytokines, including TNF- $\alpha$, IL- 6 , IL-1 $\beta$, and MCP-1 [27-29]. Numerous studies support the notion that inflammation, characterized by elevated cytokines, play a pivotal role in the pathogenesis of cognitive impairment [30, 31]. Therefore, these results suggest that vitamin $D$ might play a key role in cognitive impairment of patients with HT.

Several limitations of the study should be presented. First, the limited number of HT patients reduced the statistical power of the study. Second, the time variation of vitamin $D$ levels makes it preferable to perform the measurements on the same day. Third, the cross-sectional nature of the study precludes any conclusions on the possbile causal relationship between vitamin D levels and cognitive impairment in patients with HT. Forth, the study subjects came from only one clinic, which limited the generalization of the findings of the study. Fifth, it was not possible totest the correlation between 25(OH)D levels and MoCA scores in the control cohort due to lack of MoCA scores of healthy volunteers. Finally, the effects of dietary intake and lifestyle manners on vitamin D levels, were not considered in this study. 


\section{Conclusion}

Our findings indicate a significant relationship of serum vitamin $\mathrm{D}$ levels with cognitive impairment in patients with HT. Further studies should be encouraged to replicate our findings in larger populations, using a comprehensive battery of tests reduced to selected cognitive domains.

\section{Abbreviations}

25(OH)D: 25-hydroxyvitamin D; FT3: Free-triiodothyronine; FT4: Free

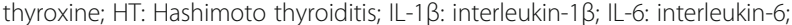
MCl: Mild cognitive impairment; MCP-1: Monocyte chemoattractant protein1; MoCA: Montreal Cognitive Assessment score; TgAbs: Anti-thyroglobulin antibodies; TNF-a: Tumor necrosis factor alpha; TPOAbs: Anti-thyroid peroxidase antibodies; TSH: Thyroid-stimulating hormone

\section{Acknowledgements}

None.

\section{Funding}

None.

\section{Availability of data and materials}

The study is currently in progress and therefore study data is not available.

\section{Authors' contributions}

JX designed the study. HJY and WZC conducted the statistical analysis. XYZ, HS, XQX, SAX, YS, LJC and QZ collected the clinical data. JX wrote, reviewed and edited the manuscript. All authors read and approved the final manuscript.

\section{Ethics approval and consent to participate}

Written informed consents were obtained from all subjects and the study was approved by the Ethics Committee of the First Affiliated Hospital of Jiaxing University.

\section{Consent for publication}

Not applicable.

\section{Competing interests}

The authors declare that they have no competing interest.

\section{Publisher's Note}

Springer Nature remains neutral with regard to jurisdictional claims in published maps and institutional affiliations.

\section{Author details}

${ }^{1}$ Department of Emergency, First Affiliated Hospital of Jiaxing University, Jiaxing, Zhejiang Province, China. ${ }^{2}$ Department of Endocrinology, First Affiliated Hospital of Jiaxing University, Jiaxing, Zhejiang Province, China.

Received: 13 August 2018 Accepted: 8 November 2018

Published online: 26 November 2018

\section{References}

1. Djurovic M, Pereira AM, Smit JWA, Vasovic O, Damjanovic S, Jemuovic Z, Pavlovic D, Miljic D, Pekic S, Stojanovic M, et al. Cognitive functioning and quality of life in patients with Hashimoto thyroiditis on long-term levothyroxine replacement. Endocrine. 2018.

2. Leyhe T, Mussig K. Cognitive and affective dysfunctions in autoimmune thyroiditis. Brain Behav Immun. 2014:41:261-6.

3. LeMoult J, Gotlib IH. Depression: a cognitive perspective. Clin Psychol Rev. 2018.

4. Scanlan JM, Binkin N, Michieletto F, Lessig M, Zuhr E, Borson S. Cognitive impairment, chronic disease burden, and functional disability: a population study of older Italians. Am J Geriatr Psychiatr. 2007;15(8): $716-24$

5. Amer M, Qayyum R. Relation between serum 25-hydroxyvitamin D and $\mathrm{C}$-reactive protein in asymptomatic adults (from the continuous
National Health and nutrition examination survey 2001 to 2006). Am J Cardiol. 2012:109(2):226-30.

6. Perez-Lopez FR, Chedraui P, Fernandez-Alonso AM. Vitamin D and aging: beyond calcium and bone metabolism. Maturitas. 2011;69(1):27-36.

7. Sommer A, Fabri M. Vitamin D regulates cytokine patterns secreted by dendritic cells to promote differentiation of IL-22-producing T cells. PLoS One. 2015;10(6):e0130395.

8. Annweiler C, Dursun E, Feron F, Gezen-Ak D, Kalueff AV, Littlejohns T, Llewellyn DJ, Millet P, Scott T, Tucker KL, et al. 'Vitamin D and cognition in older adults': updated international recommendations. J Intern Med. 2015; 277(1):45-57.

9. Eyles DW, Smith S, Kinobe R, Hewison M, McGrath JJ. Distribution of the vitamin $\mathrm{D}$ receptor and 1 alpha-hydroxylase in human brain. J Chem Neuroanat. 2005;29(1):21-30

10. Beydoun MA, Hossain S, Fanelli-Kuczmarski MT, Beydoun HA, Canas JA, Evans MK, Zonderman AB. Vitamin D status and intakes and their association with cognitive trajectory in a longitudinal study of urban adults. J Clin Endocrinol Metab. 2018;103(4):1654-68.

11. Chen RH, Zhao XH, Gu Z, Gu PL, Zhou B, Zhu ZH, Xu LY, Zou YF, Jiang XZ. Serum levels of 25 -hydroxyvitamin $D$ are associated with cognitive impairment in type 2 diabetic adults. Endocrine. 2014:45(2):319-24.

12. Cheng Z, Lin J, Qian Q. Role of vitamin D in cognitive function in chronic kidney disease. Nutrients. 2016;8(5).

13. Goodwill AM, Szoeke C. A systematic review and meta-analysis of the effect of low vitamin D on cognition. J Am Geriatr Soc. 2017;65(10):2161-8.

14. Ouma S, Suenaga M, Bolukbasi Hatip FF, Hatip-Al-Khatib I, Tsuboi Y, Matsunaga $Y$. Serum vitamin D in patients with mild cognitive impairment and Alzheimer's disease. Brain Behav. 2018;8(3):e00936.

15. Bakr HG, Meawed TE. Relevance of $25(\mathrm{OH})$ vitamin D deficiency on Hashimoto's thyroiditis. Egypt J Immunol. 2017;24(2):53-62.

16. Nalbant A, Aydin A, Karacan A, Onmez A, Tamer A, Cinemre H. Association of vitamin $D$ insufficiency/deficiency with thyroid artery Doppler ultrasonography in patients with Hashimoto thyroiditis. Pakistan J Med Sci. 2017:33(2):295-9.

17. Wang J, Lv S, Chen G, Gao C, He J, Zhong H, Xu Y. Meta-analysis of the association between vitamin $D$ and autoimmune thyroid disease. Nutrients. 2015;7(4):2485-98

18. Nasreddine ZS, Phillips NA, Bedirian V Charbonneau S, Whitehead V, Collin I, Cummings JL, Chertkow $\mathrm{H}$. The Montreal cognitive assessment, MoCA: a brief screening tool for mild cognitive impairment. J Am Geriatr Soc. 2005; 53(4):695-9.

19. Durk MR, Han K, Chow EC, Ahrens R, Henderson JT, Fraser PE, Pang KS. 1alpha,25-Dihydroxyvitamin D3 reduces cerebral amyloid-beta accumulation and improves cognition in mouse models of Alzheimer's disease. J Neurosci. 2014:34(21):7091-101.

20. Garcion E, Wion-Barbot N, Montero-Menei CN, Berger F, Wion D. New clues about vitamin $D$ functions in the nervous system. Trends Endocrinol Metab. 2002;13(3):100-5.

21. Morello M, Landel V, Lacassagne E, Baranger K, Annweiler C, Feron F, Millet P. Vitamin D improves neurogenesis and cognition in a mouse model of Alzheimer's disease. Mol Neurobiol. 2018:55(8):6463-79.

22. Burne TH, McGrath JJ, Eyles DW, Mackay-Sim A. Behavioural characterization of vitamin D receptor knockout mice. Behav Brain Res. 2005:157(2):299-308.

23. Kalueff AV, Lou YR, Laaksi I, Tuohimaa P. Impaired motor performance in mice lacking neurosteroid vitamin D receptors. Brain Res Bull. 2004: 64(1):25-9.

24. Zou J, Minasyan A, Keisala T, Zhang Y, Wang JH, Lou YR, Kalueff A, Pyykko I, Tuohimaa P. Progressive hearing loss in mice with a mutated vitamin D receptor gene. Audiol Neuro-otol. 2008;13(4):219-30.

25. Mikos H, Mikos M, Rabska-Pietrzak B, Niedziela M. The clinical role of serum concentrations of selected cytokines: IL-1beta, TNF-alpha and IL-6 in diagnosis of autoimmune thyroid disease (AITD) in children. Autoimmunity. 2014;47(7):466-72

26. Sun L, Zhang X, Dai F, Shen J, Ren C, Zuo C, Zhang Q. Elevated interleukin1 beta in peripheral blood mononuclear cells contributes to the pathogenesis of autoimmune thyroid diseases, especially of Hashimoto thyroiditis. Endocr Res. 2016;41(3):185-92

27. Eksioglu U, Atilgan HI, Yakin M, Yazihan N, Altiparmak UE, Yumusak N, Korkmaz M, Demir A, Ornek F, Aribal Ayral P, et al. Antioxidant effects of vitamin $D$ on lacrimal glands against high dose radioiodine-associated damage in an animal model. Cutan Ocul Toxicol. 2018:1-21. 
28. Farhangi MA, Mesgari-Abbasi M, Hajiluian G, Nameni G, Shahabi P. Adipose tissue inflammation and oxidative stress: the ameliorative effects of vitamin D. Inflammation. 2017;40(5):1688-97.

29. Farhangi MA, Mesgari-Abbasi M, Nameni G, Hajiluian G, Shahabi P. The effects of vitamin $D$ administration on brain inflammatory markers in high fat diet induced obese rats. BMC Neurosci. 2017;18(1):81.

30. Culley DJ, Snayd M, Baxter MG, Xie Z, Lee IH, Rudolph J, Inouye SK, Marcantonio ER, Crosby G. Systemic inflammation impairs attention and cognitive flexibility but not associative learning in aged rats: possible implications for delirium. Front Aging Neurosci. 2014;6:107.

31. Takeda S, Sato N, Morishita R. Systemic inflammation, blood-brain barrier vulnerability and cognitive/non-cognitive symptoms in Alzheimer disease: relevance to pathogenesis and therapy. Front Aging Neurosci. 2014;6:171.

Ready to submit your research? Choose BMC and benefit from:

- fast, convenient online submission

- thorough peer review by experienced researchers in your field

- rapid publication on acceptance

- support for research data, including large and complex data types

- gold Open Access which fosters wider collaboration and increased citations

- maximum visibility for your research: over $100 \mathrm{M}$ website views per year

At $\mathrm{BMC}$, research is always in progress.

Learn more biomedcentral.com/submissions 